The liberalism of Maria Zambrano: from Ortega and Blas Zambrano to the League for Social Education

\title{
El liberalismo de María Zambrano: de Ortega y Blas Zambrano a la Liga de Educación Social
}

\author{
Juan Bagur Taltavull
}

Universidad Complutense de Madrid. juanbagur@ucm.es

DOI: http://doi.org/10.15366/bp2019.22.025

Bajo Palabra. II Época. № 22. Pgs: 459-476

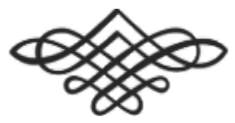


Recibido: 14/12/2017

Aprobado: 02/10/2017

\section{Resumen}

El artículo estudia el liberalismo de la filósofa española María Zambrano, atendiendo tanto a sus fuentes intelectuales como a su proyección en la Liga de Educación Social. En este sentido, se reconstruye el influjo de su padre Blas Zambrano y también el de su maestro José Ortega y Gasset, todo ello dentro del contexto político de la dictadura de Miguel Primo de Rivera.

Palabras clave: María Zambrano, Ortega y Gasset, Blas Zambrano, liberalismo, democracia, filosofía política.

\section{Abstract}

This article aims to study the liberalism of the Spanish philosopher María Zambrano, focusing on both its intellectual origins and its repercussion in the League for Social Education. In this sense, the influence of her father Blas Zambrano and her master José Ortega y Gasset are analyzed, all in the context of the Dictatorship of Miguel Primo de Rivera

Keywords: Maria Zambrano, Ortega y Gasset, Blas Zambrano, liberalism, democracy, political philosophy. 


\section{Introducción}

El objetivo del presente trabajo es el estudio del pensamiento y la acción política de María Zambrano entre los años 1928 y 1930. Es un periodo que forma parte de la primera etapa de la configuración de su filosofía, que abarca hasta $1934^{1}$, y que está delimitado por dos hechos encuadrados políticamente en la dictadura de Primo de Rivera: en 1928 participó en la creación de la Liga de Educación Social, y en 1930 publicó su primer libro, Horizonte del liberalismo.

Con la voluntad de comprender la Liga desde sus precedentes, y asimismo el pensamiento de María Zambrano a partir de sus orígenes, reconstruiremos no únicamente el eje horizontal en que se inscribe, sino también el vertical ${ }^{2}$. Esto es, rastrearemos el influjo de Ortega y Gasset, inscribiendo a ambos autores en el fenómeno de la actuación política a través de las "Ligas". Para ello partimos de un hecho histórico, del que tal vez no fuera consciente Zambrano pero en el que vemos inscrita su actuación: existen en esta forma de actuación intelectual dos tradiciones correspondientes con otras tantas culturas políticas, la una elitista, y la otra popular. Históricamente, 1907 es un año en el que aparecieron juntas, cuando Ortega y Nuñez Arenas fundaron la Fabian Society. Sin embargo, dicha actuación no tuvo relevancia, y esto se debe a que las dos tradiciones señaladas hacían incompatible la actuación conjunta de los dos. Arenas fundará la Escuela Nueva en 1910, mientras que Ortega formará en 1913 la Liga de Educación Política.

Desde esta base, la hipótesis que planteamos es la siguiente: la Liga de Educación Social supone la superación de la escisión anterior, incorporando en su seno la tradición emanada de Ortega y la derivada de Arenas. Como hipótesis secundarias señalaremos dos: primero, que esto se debe a que María Zambrano es heredera de ambos intelectuales - del segundo por vía de su padre Blas Zambrano-; segundo,

\footnotetext{
El presente artículo, y la comunicación en que se basa, han sido realizados como parte de una investigación doctoral titulada "La idea de nación en el pensamiento y la acción política de José Ortega y Gasset", dirigida por Juan Pablo Fusi Aizpurúa y Anonio López Vega, y financiada por una beca FPU del Ministerio de Educación, Cultura y Deporte.

${ }^{1}$ Moreno Sanz, J., "Presentación", Zambrano, M., "Horizonte del Liberalismo", Obras completas. I, Libros (19301939), Barcelona, Galaxia Gutenberg: Círculo de Lectores, 2015, p.26.

${ }^{2}$ Recurrimos al paradigma que plantea C.E. Schorske, en virtud del que todo objeto intelectual es fruto del entrecruzamiento de dos ejes, uno vertical-diacrónico, y otro horizontal-sincrónico. Vid.: Schorske, C. E., La Viena de fin de siglo: política y cultura, Buenos Aires, Siglo XXI, 2011, p. 16.
} 
que esto es posible porque la malagueña también "supera" la filosofía orteguiana, avanzando en su libro de 1930 la Razón Poética ${ }^{3}$.

\section{España entre Blas Zambrano y Ortega y Gasset}

La dictadura de Primo de Rivera contó con la oposición de gran cantidad de estudiantes como María Zambrano. Su amigo José López Rey narra cómo en 1924, el mismo en que se fundó la Unión Patriótica, nació la Federación Universitaria Escolar de Madrid ${ }^{4}$. Frente al nacionalismo conservador de aquélla, defendían un nacionalismo proyectivo que forma parte de la cultura política liberal en la que se integran también Ortega y Blas Zambrano, y que se remonta a Nietzsche. Oponía la Vaterland o patria de los padres, a la Kinderland, o patria de los hijos, por considerarla res facta y antes que $n a t a^{5}$. Ya en 1910 Ortega le nombra directamente ${ }^{6}$, y Unamuno vuelve a repetirlo en una frase que dejará una viva impronta en López Rey: en la carta que envía desde su exilio parisino, vetada, pero aun así repartida en octavillas, consignaba el vasco el amor a España, "más nuestra hija que nuestra madre" 7 .

Desde 1926, tres años después del golpe militar, María Zambrano se estableció en Madrid y acudió a la Universidad Central. Allí fue alumna de José Ortega y Gasset, del que diría en 1943 que "ha sido y será mi maestro" ${ }^{8}$. Pero también pervivieron en ella ideas procedentes de su padre Blas Zambrano, quien le introdujo en un "círculo donde se entremezclan las relaciones filiales con las intelectuales" 9 Nacido en 1874, y por tanto hombre del 98, Blas Zambrano estuvo influido por el krausismo, mostrando desde el principio una idea de nación proyectiva. Escribe así que España "ha de dejar de ser una nación vieja", y "siendo jóvenes vosotros, esto es, los jóvenes de España, durante mucho tiempo, es como España dejará de ser vieja" ${ }^{10}$. Además es esencial su concepción de la educación, considerando su ausencia como el fundamento del mal social. En una conferencia dada en 1900 afirma que

\footnotetext{
${ }_{3}^{3}$ Moreno Sanz, J., "Presentación”, op. Cit., p. 28.

${ }^{4}$ López Rey, J., Los estudiantes frente a la dictadura. Madrid, Javier Morata, 1930, pp. 5-6.

5 Nietzsche, F., Más allá del bien y del mal, Madrid, Alianza Editorial, 2003, p. 219.

6 Ortega y Gasset, J., "La pedagogía social como programa político", Obras completas. Tomo II (1916), Madrid, Taurus: Fundación José Ortega y Gasset, 2010, pp. 86-102, p.89.

7 López Rey, J., Los estudiantes..., op. cit., p. 22.

8 Zambrano, M., "Conferencia de San Juan de Puerto Ricos sobre Ortega y Gasset", Escritos sobre Ortega. Edición, introducción y notas de Ricardo Tejada, Madrid, Trotta, 2011, pp. 247-266, p. 248.

9 Mora, J.L., "Introducción”, Zambrano, B. J., Artículos, Relatos y Otros Escritos, Diputación Provincial de Badajoz, Badajoz, 1998, pp. 3-42, p. 4.

10 Zambrano, B., "Juventud”, Artículos.., op. cit., pp. 208-211, p. 208 y 211.
} 
"la plena educación de todos los hombres será el único medio de que se acelere la revolución social”. Apostaba por la formación de los obreros, y la definía en sentido un "integral" que incluyera la "educación de la voluntad y de los sentimientos ${ }^{11}$. Este concepto será importante en María, quien lo retoma en 1955 para vincular la educación moral al imperativo de "ser persona íntegramente" ${ }^{2}$. La diferencia es el carácter menos democrático de su padre, para el que esta "reconstitución nacional" desde la pedagogía partía de un "elitismo pedagógico-social" ${ }^{13}$. Aunque es un aristocratismo moral, igual al que tiene Ortega al hablar en 1913 del socialismo -en cuyo partido militó Blas entre 1917 y 1920 - como "estado social donde influyen decisivamente los mejores" ${ }^{14}$. María Zambrano no será ajena a esta concepción en la que coinciden durante unos ańos su padre y su maestro. Todavía en 1937 escribirá en términos casi idénticos que el PSOE formó en España una "verdadera aristocracia moral e intelectual". Frene a la tesis de la rebelión de las masas, plantea que constituían "una de las esencias más "nacionales" de nuestra España"15.

Pero aunque los dos personajes llegaron a defender una misma concepción aristocrática del socialismo, el método para alcanzarlo por vía de la educación es distinto. Para Ortega es la Universidad, mientras que Blas Zambrano estuvo directamente relacionado con la Escuela Nueva ${ }^{16}$. Había estudiado Magisterio en Sevilla en 1883, siendo su Universidad, después de la de Madrid, la de mayor presencia de krausistas ${ }^{17}$, y en tanto que maestro organizó La Obra, entidad obrera formada en 1899 por intelectuales, republicanos, ácratas y socialistas. El carácter de antecesor de la Liga de Educación Social se manifiesta en que, como ocurrirá con los movimientos universitarios en los que se comprometería María, el principal enemigo de esta institución, o por lo menos del órgano $X$, serían grupos católicos. La cuestión clerical fue clave en el combate intelectual de principios del siglo XX, y el institucionismo -la ILE precisamente surgió en 1876 ante el ataque del neocatólico Orovio- fue la principal alternativa al nacionalcatolicismo ${ }^{18}$.

\footnotetext{
Zambrano, B., "Resumen de la conferencia”, Artículos..., op. cit., pp. 97-107, pp. 100, 103 y 104.

12 Zambrano, M., "Don José”, Escritos sobre Ortega, op. cit., pp. 125-127, p. 126.

13 Zambrano, B., "La despedida”, Artículos..., op. cit., pp.435-467, p.456.

${ }^{14}$ Ortega y Gasset, J., "Socialismo y aristocracia”, Obras completas. Tomo I (1902-1915), Madrid, Taurus: Fundación José Ortega y Gasset, 2005, pp.621-633, p. 623.

15 Zambrano, M., "Los intelectuales en el drama español. Los que han callado", Escritos sobre Ortega, op. cit., pp.242-244, p. 243.

16 Calvo González, J., "Sobre horizonte del liberalismo (1930), o María Zambrano en claroscuro”, Revista telemática de filosofia del derecho (RTFD), no8 (2004-2005), pp. 99-124, p. 100.

${ }_{17}$ Marset, J. C., María Zambrano. I, los años de formación, Sevilla, Fundación José Manuel Lara, 2004, p. 43 y 84.

${ }_{18}$ Utilizamos esta categoría para referir no la ideología del franquismo, sino aquélla que, desembocando en ésta, es sin embargo muy anterior. Según Alfonso Botti, entre 1898 y 1923 se va distinguiendo del tradicionalismo y el ultramontanismo. Vid.: Botti, A., Cielo y dinero: el nacionalcatolicismo en España, 1881-1875, Madrid, Alianza Editorial, 2008, p.54.
} 
Como hará luego su hija, Blas colabora en El Liberal desde 1907, y en otras publicaciones como La Escuela Moderna, y ya instalado en Segovia inicia una etapa que será determinante en ella. En 1909 fue admitido en la Sociedad Económica de Amigos del País, que daría paso tras su extinción a la Universidad Popular Segoviana. Participó en esta institución junto con Antonio Machado, que tanto influiría en María, o José Tudela, amigo de Ortega; en lo que muestra la continuidad de los ideales ilustrados con los del liberalismo de matriz institucionista. Una idea de España de nuevo alternativa a la conservadora ${ }^{19}$, que confirma la tesis de autores como Juan Marichal al sostener la existencia de una tradición liberal española emanada del siglo XVIII ${ }^{20}$.

La Universidad Popular atrajo a conferenciantes ilustres como Américo Castro, García Morente, Eugenio d'Ors, María de Maeztu, Luzuriaga, Gregorio Marańón...Lo mismo por tanto que iniciativas orteguianas del estilo de la Residencia de Estudiantes. Pero con la diferencia de que su destino principal eran los obreros, a los que ofrecía clases nocturnas desde 1920 y para lo que se estableció la primera biblioteca circular de Segovia. María Zambrano conocería esta iniciativa no únicamente por su padre, sino también por vía directa porque daría conferencias -el 14 de febrero de 1920 la de "Noción de la cultura"-, y entre 1925 y 1926 sería profesora. Destacable es también que la intelectualidad segoviana promovió el amor y conocimiento a la patria chica en el más puro sentido noventayochista, buscando sus esencias medievales y su intrahistoria. Blas Zambrano dirigió en 1917 la revista Castilla, y los Zuloaga -Ignacio también fue amigo de Ortega-, instalaron su taller en esta ciudad. Tal vez la valoración positiva que María Zambrano haría de la generación del 98 se debe a estas circunstancias, dado que "Segovia está en los orígenes intelectuales de María Zambrano ${ }^{21}$.

Ortega y Gasset no fue ajeno a la cultura política en la que se integraba la Escuela Nueva, ni tampoco a la educación de los obreros. Dio varias conferencias en la Casa del Pueblo, y en una intervención de 1910 en El Sitio define al socialismo en términos muy similares a los de Blas Zambrano. Reconoce que "el problema español es un problema pedagógico" que únicamente se solucionará con la "socialización de la escuela", que ha de ser única y laica ${ }^{22}$. Pero esto lo escribe en la etapa de su pensamiento más cercana al socialismo, que corresponde con su formación neokan-

\footnotetext{
${ }_{19}$ El nacionalcatolicismo hizo del XVIII el origen de los males de España: Ramiro de Maeztu dirá en 1934 que la "extranjerización" de los Borbones era la fuente del mal, y si bien al tiempo reconocía la importancia de las Sociedades Económicas de Amigos del País, no por ello deja de llamar "Antipatria” a la España nacida de allí. Vid., Maeztu, R., Defensa de la Hispanidad, Madrid, Homo Legens, 2005, p. 6.

${ }^{20}$ Marichal, J., El secreto de España: Ensayos de historia intelectual y politica, Madrid, Taurus, 1996, p.19.

${ }_{21}$ Abellán, J.L., María Zambrano: una pensadora de nuestro tiempo, Rubí, Barcelona, Anthropos, 2006, p. 32.

22 Ortega y Gasset, J., "La pedagogía social..., op. cit., pp. 97 y 99.
} 
tiana. Desde 1912 cambiará su postura poco a poco, abandonando el socialismo en favor del reformismo, y desarrollando con la Razón vital fu filosofía original ${ }^{23}$. La Liga de Educación Política que funda en 1913 se inscribe ya en un marco elitista, dentro además del primer "partido de la intelectualidad", el Partido Republicano Reformista de Melquíades Álvarez ${ }^{24}$.

\section{La Liga de Educación Social: origen, naturaleza y método de actuación}

LAS Ligas FUERON Un INSTRUMENTO DE ACTUACión intelectual muy difundido en la Europa del momento, destacando en Francia la Liga para la Defensa de los Derechos del Hombre y del Ciudadano -imitada en España en 1913 por Luís Simarro-, y en Gran Bretańa la Sociedad Fabiana -que también quiso copiarse en 1907 desde el Ateneo madrileño. Además de la Joven España de 1910, en nuestro contexto destacó la Liga de Educación Política Española, presentada con el discurso "Vieja y nueva política" de marzo de 1914. Aunque duró poco, fue el primer intento serio de unir a los intelectuales espańoles y por ello quedaría en su imaginario. Por eso un año después Ortega recibió una carta firmada por un tal Salvador Giner en la que le decía que después del fracaso de todas las ligas anteriores, era menester formar una "Liga que nos defienda todos los derechos que la Constitución nos ha reconocido". Como hará Zambrano, reivindicaba tanto la herencia de la Liga orteguiana como el socialismo, apelando a la inclusión de las "nuevas generaciones" 25 .

López Rey parece atribuir un carácter más netamente político a la Liga de Educación Social, puesto que buscaban el apoyo de "algunos hombres maduros de izquierda" y su actividad se centraba en reclamar el compromiso del "hombre de izquierda inactiva" ${ }^{26}$. La Liga de Educación Política no se había mostrado tan abiertamente izquierdista, y de hecho Maeztu señaló a Ortega que su planteamiento era tan ambiguo que los conservadores podrían aceptarlo ${ }^{27}$. El propio Gabriel Maura escribió al filósofo indicándole que su propuesta no era muy alejada de la de su padre, el gran líder

\footnotetext{
${ }_{23}$ Sobre este proceso, ver Bagur Taltavull, J., La idea de nación en la nueva politica orteguiana. Desarrollo y crisis del patriotismo fenomenológico (1909-1916), Madrid, Ápeiron Ediciones, 2016.

24 Suárez Cortina, M., El reformismo en España: republicanos y reformistas bajo la monarquía de Alfonso XIII, Madrid, Siglo XXI de España, 1986, p.81.

25 Giner, S., “Carta a Ortega y Gasset. Tenerife, 31-VIII-1916”, Fundación Ortega-Marañón, Fondo José Ortega y Gasset, Sig: C-89/20.

${ }^{26}$ López Rey, J., Los estudiantes..., op. cit., pp. 50-54.

${ }_{27}$ Citado en González Cuevas, P.C., "Maeztu y Ortega: dos intelectuales ante la crisis de la Restauración", Gómez-Ferrer Morant, G., y Sánchez, R. (coords.): Modernizar España: proyectos de reforma y apertura internacional (1898-1914), Madrid, Biblioteca Nueva, 2007, pp.231-252, p.244.
} 
conservador ${ }^{28}$. María Zambrano por su parte resaltará en 1952 que lo que pensaba en 1928 era que "no se trata de hacer política", sino de abrir paso a la vida de Espańa que se mostraba en oposición a la "falsedad oficial" 29 . Lo mismo que Ortega, dado que en 1914 indicaba que no buscaba el poder sino aumentar la vitalidad de España ${ }^{30}$. El prospecto de la Liga de Educación Social afirmaba que "un panorama social surge y se impone, y un cambio de vida adecuado ha de resolver sus problemas" ${ }^{31}$.

Para llevar a cabo esta misión, las dos instituciones tenían en común la apuesta por una respuesta "científica", esto es, basada en el estudio de la realidad y no en la utopía. Había dicho Ortega años antes a Zulueta que era menester "ir formando la ciencia del fenómeno Espańa”, "intuir España, irla construyendo como una física" ${ }^{2}$. De modo similar, Zambrano planteaba la necesidad de "construir la vida española" ${ }^{33}$ y hablará de utilizar la intuición por ser la vía de análisis del revolucionario, que desconfía de la razón que pretende agotar dentro de sus límites la realidad $^{34}$. Avanza la Razón poética aplicándola a la política, y ello explica una de sus principales diferencias con respecto a Ortega, quien utiliza la Razón vital y así una "política de base fenomenológica" 35 .

Otra divergencia importante se refiere al sector al que se dirigían sus prospectos. El de María Zambrano hace mención directa a la integración dentro de la vida política de obreros y mujeres. Si Ortega se limitaba a mencionar la "cuestión obrera" animando al PSOE a identificarla con la "cuestión nacional" ${ }^{66}$, la Liga de Educación Social apostaba por una integración del sector obrero como tal: "una clase social, joven y poderosa, el proletariado, se prepara a estructurarse”. Además, se hacía mención expresa de la mujer, que es el otro de los sectores que entró como protagonista del siglo XX. "La mujer interviene en la vida desconcertando el antiguo orden con actitudes nuevas" ${ }^{37}$, señala, mientras que el texto de Ortega ni siquiera las menciona. Esto es importante porque el hecho de radicar el protagonismo en los

${ }_{28}$ Maura, G., “Carta a José Ortega y Gasset. 15-V-1914”, Fundación Ortega-Marañón, Fondo José Ortega y Gasset, Sig: C-67/21C.

29 Zambrano, M., "Delirio y destino", Obras completas. VI, Parte II. Delirio y Destino (1952), Barcelona, Galaxia Gutenberg: Círculo de Lectores, 2014, pp. 804-1109, p. 867.

30 Ortega y Gasset, J., "Vieja y nueva política”, Obras completas. Tomo I..., op. cit., pp.709-737, p.716.

31 Citado en López Rey, J., Los estudiantes..., op. cit., p. 54.

32 Ortega y Gasset, J., “Carta a Luís de Zulueta. 15-XI-1911”, Fundación Ortega-Marañón, Fondo José Ortega y Gasset, Sig: CD-Z/9.

33 Zambrano, M., "Delirio y destino..., op. cit., p. 867.

${ }^{34}$ Zambrano, M., "Horizonte del liberalismo..., op. cit., p. 74.

35 Cerezo Galán, P., “Ortega y la regeneración del liberalismo: tres navegaciones y un naufragio”, en Llano Alonso, F., y Castro Sáenz, A. (eds.), Meditaciones sobre Ortega y Gasset, Madrid, Tebar, 2005, pp. 625-646, p. 637.

36 Ortega y Gasset, J., "Prospecto de la Liga de Educación Política Española", Obras completas. Tomo I...,op. cit., pp. 738-744, p. 741.

37 López Rey, J., Los estudiantes..., op. cit., p. 55. 
intelectuales, o en éstos junto con el pueblo, repercute en el método de actuación. La Liga de Educación Política únicamente llevó a cabo una actividad pública, la conferencia "Vieja y nueva política", canalizándose su herencia desde 1915 a través de un semanario de intelectuales, España. La Liga de Educación Social por su parte centró sus actividades en ámbitos de socialización obrera, destacando en cuanto la conferencia que dio Zambrano en un local de cigarreras, esto es, ante un público no únicamente trabajador sino también femenino ${ }^{38}$.

Por otro lado, un elemento que conecta a las dos ligas es su apuesta por la descentralización de la actividad política frente a lo que Ortega llamará en estos años "madrileńismo" ${ }^{39}$. Partiendo de la base de que la "circunstancia" espańola era la provincia, Ortega propuso en 1914 crear grupos provinciales, que quiso impulsar desde España. En esta línea, Zambrano pretendía expandir su movimiento por toda España, y afirmaría sobre ella que "en cada Universidad de provincias hay ya grupos, gente nuestra" ${ }^{40}$. López Rey recuerda que la Liga "organizó conferencias en ciudades y pueblos" ${ }^{\text {"1 }}$, y de entre ellas es conocida la que ofreció junto a Zambrano en Valladolid el 13 de diciembre de $1928^{42}$. En esta línea, si España fue el "órgano de los intelectuales reformistas" ${ }^{43}$, la Liga de Educación Social careció de un periódico propio. Pero fiel a su regionalismo contó con secciones en periódicos de diversas regiones: El Norte de Castilla, el santanderino La Región, el Diario de Palencia, La Libertad en Badajoz, La Nau catalana, y los madrileños La Libertad y El Liberal. En este último estuvo desde pronto adscrita Zambrano, publicando una quincena de artículos en las secciones "Aire Libre" y "Mujeres" ${ }^{44}$.

Además, es contrapuesto el modelo que seguían las intervenciones: en la Liga orteguiana se había planteado evitar reuniones masificadas, y eliminar el caudillismo permitiendo que cada vez tomara la palabra una persona distinta: un especialista que utilizaría su conocimiento para encauzar el debate. Así por ejemplo, en una de las dos reuniones documentadas el propio Ortega tomó la palabra para exponer su idea de las generaciones ${ }^{45}$. En el caso de Zambrano, expresamente afirma que no querían centrarse en los militantes, sino ir a hablar a los obreros, y más que eso, a

\footnotetext{
38 Zambrano, M., "Delirio y destino..., op. cit., p. 880.

39 Ortega y Gasset, J., "La redención de las provincias", Obras completas. Tomo IV (1926-1931), Madrid, Taurus: Fundación José Ortega y Gasset, 2004, pp.671-856, p.702.

40 Zambrano, M., "Delirio y destino..., op. cit., p. 867.

${ }^{41}$ López Rey, J., Los estudiantes..., op. cit., p. 55.

${ }^{42}$ Zambrano, M., "Delirio y destino..., op. cit., p.866.

43 Redondo, G., Las empresas políticas de José Ortega y Gasset: "El Sol”, "Crisol”, "Luz"(1917-1934), Madrid, Rialp, 1970 , p.96.

44 Zambrano, M., "Delirio y destino..., op. cit., pp. 878-879.

45 Bagur Taltavull, J., "José Ortega y Gasset en el movimiento reformista: la Liga de Educación Política Española como proyección del "patriotismo fenomenológico"”, Ab Initio, no 10 (2014), pp.153-188, p. 169.
} 
"convertirles". Rememorando la conferencia con las cigarreras sostiene que "no es que les hubiesen hablado a ellas, sino con ellas" ${ }^{46}$. Al mismo tiempo, su Liga recurrió a otra vía más informal y destinada al público estudiantil: las hojas impresas, de carácter clandestino por la naturaleza del régimen político. López Rey recuerda que, en el contexto de las huelgas universitarias -algunas impulsadas por integrantes como Antolín Casares-, se reunieron en el café Spiedum para redactar unas notas que pudieran "orientar a la masa escolar". En una, González López trataba la cuestión de la libertad y la ciudadanía, y él mismo redactó otra ${ }^{47}$.

Por otro lado, en lo que es otra muestra de las consecuencias políticas de la Razón poética, la Liga de Educación Social buscó la compenetración de generaciones, llamando "maduros" a quienes "en otro momento hubieran sido llamados "viejos»" "48. Frente a un Ortega al que creerá algo anclado en la tradición de pensamiento occidental que, entre otras muchas cosas, apuesta por el progreso; Zambrano, desde Bergson o Nietzsche, desarrolla la teoría de la "multiplicidad de los tiempos". Aunque también cita Meditaciones del Quijote, no parece su maestro la principal influencia cuando apela a romper el "tiempo cadena" y a sustituirlo por el "instante", ligado a la vivencia temporal de los jóvenes ${ }^{49}$. El orteguiano "vivir es convivir" es resignificado desde esta ruptura del orden lógico del tiempo, que permite la coexistencia de jóvenes y maduros. En ellos ve el ímpetu creador de una "tradición crítica", de una "España antigua, universal, ancha", nunca asfixiada por la "España oficial" y siempre dispuesta a "convertir" a los demás ${ }^{50}$.

El grupo de hecho se constituyó con ayuda de los "maduros". Si la Liga de Educación Política nació en el marco del Partido Reformista, la Liga de Educación Social lo hizo en el de la FUE. En la Residencia de Estudiantes organizaron López Rey, María Zambrano y otras personas una primera reunión, que ella describe en términos similares a los de Ortega. Éste afirmó al reunir por vez primera a sus seguidores que "hasta hace poco vivíamos ajenos unos de otros" 51 , y antes apeló a crear "una convivencia omnímoda, una fraternidad" 52 ; y ella recuerda que los antes solitarios formaron "un grupo, una unidad fraternal" en la Residencia ${ }^{53}$. De esta primera entrevista, surgió el compromiso de ir en grupos de dos o tres a visitar a los "maduros": Giral, Sánchez Román, Marañón, Pérez de Ayala, Azaña...Ortega no porque estaba en Argentina.

\footnotetext{
46 Zambrano, M., "Delirio y destino..., op. cit., pp. 880-881.

${ }^{47}$ López Rey, J., Los estudiantes..., op. cit., pp. 56 y 96.

48 Zambrano, M., "Delirio y destino..., op. cit., p. 874.

49 Ortega y Gasset, J., "Conversaciones de la Liga de Educación Política”, Fundación Ortega-Marañón, Fondo José Ortega y Gasset, Sig: B-84/3.

50 Zambrano, M., "Delirio y destino..., op. cit., pp. 867 y 874.

51 López Rey, J., Los estudiantes..., op. cit., p. 55.

52 Ortega y Gasset, J., "Carta a Luís de Zulueta..., op. cit.

53 Zambrano, M., "Delirio y destino..., op. cit., p. 869.
} 
Zambrano destaca a tres personas. Primero, a Manuel Azaña, quien desde el principio se opuso a la Dictadura, pero que no parecía muy entusiasmado con el proyecto dado que defendía una actuación más política. Segundo, habla de Gregorio Marañón, receptivo pero que se definió a sí mismo como un "francotirador" no afecto al compromiso -elemento que se mantendría hasta su compromiso no con la entidad zambraniana, sino con la orteguiana Agrupación al Servicio de la República. Finalmente, Luís Jiménez de Asúa, joven profesor que hacía las veces de intermediario entre las dos generaciones. Zambrano y sus compañeros lograron que unos y otros se reunieran el 24 de junio de 1928 en un merendero llamado La Bombilla. Pero no resultó del todo efectivo, dado que si bien fueron escuchados, no se sintieron entendidos ${ }^{54}$. En todo caso, esto marcó el inicio de la actividad de la Liga, que fue clausurada por orden gubernativa en marzo de 1929. "Después no intentamos su reorganización -escribe López Rey-, pues quienes la formábamos hubimos de dedicar nuestra actividad a las entidades estudiantiles en batalla durante un año" 55 .

Esta cuestión intergeneracional contrasta con la concepción de Ortega. Si en 1913 llamaba a la del 98 la "generación fantasma" 56 , en "Vieja y nueva política" comienza su discurso diciendo que su generación no había tenido maestros. Considera que cada generación ha de desprenderse de los tópicos recibidos y "comenzar por ser fiel a sí misma". Esto afirma porque su concepción del devenir histórico es muy claro: cada época histórica es "transición", porque la sustancia histórica está en continuo cambio, y si coexisten modos de vivir el tiempo, es porque uno de ellos ha de ser superado: la "España oficial" que prolonga la edad fenecida, frente a la "España real", que es la fidelidad a su época ${ }^{57}$. María Zambrano utiliza categorías orteguianas, como la "España oficial" o la idea de "generación", pero su interpretación de la temporalidad hace que el resultado sea radicalmente distinto. Pero también hay que señalar que Ortega, si bien tiene una concepción despectiva de sus mayores, no asume lo propio con respecto a sí mismo cuando es la suya la generación madura. Reconoce que hay etapas de la historia donde no ha predominado la juventud, sino una "ecuación dinámica" que representan por ejemplo en Grecia Sócrates y Alcibíades. En la España de finales de los años veinte, existiría un exceso de juventud, y reivindica su papel en la historia de España ${ }^{58}$. Por ello fundará la mencionada Agrupación al Servicio de la República.

\footnotetext{
54 Ibid., pp. 869-873.

55 López Rey, J., Los estudiantes..., op. cit., p. 55.

56 Ortega y Gasset, J., "Competencia”, Obras completas. Tomo I...., op. cit., pp. 602-606, p. 603.

57 Ortega y Gasset, J., "Vieja y nueva política”, op. cit., pp. 712 y 714.

58 Ortega y Gasset, J., La rebelión de las masas. Introducción de Julián Marías, Madrid, Espasa-Calpe, 2005, pp. 247-248.
} 


\section{El horizonte liberal de la Liga de Educación Social}

EnTRAMOS AHORA EN LA DEFinición DE LA NACIÓN, que separa a los dos autores. La de Ortega es elitista, la de María Zambrano democrática, y las diferencia el concepto de masa. Como muchos en su época, Ortega temía el "hecho de las aglomeraciones", no por su carácter cuantitativo, sino su proyección cualitativa: el rebajamiento moral e intelectual consecuente del resentimiento ${ }^{59}$. Esta definición estaba ya presente en la época de la Liga de Educación Política: unos años antes de crearla, define al pueblo por oposición a la elite: las "minorías científicas" son el "no pueblo", dice a Maeztu en $1908^{60}$. Cuando habla a Zulueta de crearla, le dice que "con el pueblo ni se ha hecho jamás política ni se hará nunca. El pueblo es solo un arma en una mano. Falta la mano" ${ }^{61}$.

De esta manera Ortega se integra en una corriente de intelectuales que, desde fines del XIX, construyeron la noción de "masa" ante el temor a ser desplazados del centro de la vida pública ${ }^{62}$. Frente a esto, el "pueblo" es el concepto que emplea Zambrano desde una cultura política contraria. También percibió la irrupción del nuevo sujeto colectivo, pero lejos de atribuirle un carácter despectivo, le convierte en depósito de virtudes. Invierte el análisis orteguiano, puesto que si el maestro sostiene que la elevación al carácter protagonista de la masa es causa de la decadencia de la política, para Zambrano la política está en decadencia porque el pueblo no es su director. La cultura política en que se integra es más cercana al populismo, desarrollado en la etapa de entreguerras con fuerza equiparable al socialismo y el comunismo. Alejandro Lerroux o Blasco Ibánez representan en Espańa esta idea que tiene tres elementos: el caudillismo, el planteamiento interclasista, y la atribución de una superioridad moral al pueblo ${ }^{63}$.

María Zambrano no acude al primer factor, pero su propuesta es claramente cercana a los otros dos elementos: mediante la exaltación de las clases populares, diluye el efecto aristocrático de la minoría directora, y si lo hace es porque, precisamente contra un Ortega que vincula moralidad y elitismo, hace del pueblo español -y aquí se ve el influjo de la intrahistoria noventayochista- el depósito de la virtud humana. Los dos autores veían que existe una desmoralización en la España que componía su circunstancia, pero conciben la ética de modo muy

59 Ibid., p. 65.

${ }^{60}$ Carta a Ramiro de Maeztu en 1908. Citada en Fox, E. I., "Sobre el liberalismo socialista: cartas inéditas de Maeztu a Ortega, 1908-1915”, Kossof, D. A., y Amor y Vázquez, J. (coords.), Homenaje a Juan López Morillas: de Cadalso a Aleixandre, Madrid, Castalia, 1982, pp. 220-236, p. 225.

${ }^{61}$ Ortega y Gasset, J., "Carta a Luís de Zulueta. 15-XI-1911", op. cit.

${ }^{62}$ Carey, J., Los intelectuales y las masas: orgullo y prejuicio de la intelectualidad literaria, 1880-1930, Madrid, Siglo XXI, 2007, p. 19.

${ }^{63}$ Cruz, R., "Pueblo, Parapueblo y Contrapueblo en 1931", Moreno Luzón, J., y Del Rey, F. (eds.), Pueblo y nación. Homenaje a José Álvarez Junco, Madrid, Taurus, 2013, pp.109-125, pp.112-113. 
distinto. Para Ortega, son los intelectuales en exclusiva quienes están llamados a crear valores nuevos que hagan frente a la realidad vacía, proponer ideas que pasen después a ser creencias de la gente ${ }^{64}$. María Zambrano asume las tesis de "El tema de nuestro tiempo" (1923), pero pone en guardia ante el elitismo liberal. Como Ortega, cree que el liberalismo abstracto, el que cae en lo que él llamaba el "utopismo como método intelectual" ${ }^{65}$, no respeta la vida humana en tanto que crea un esquema atemporal que no incluye la realidad concreta. Pero esa realidad concreta ha de incluir lo "infrahumano", las pasiones, a lo que el madrileño no prestaba atención. Zambrano señala que "el hombre carnal", el "hombre masa" no se reconoce en la ética liberal, y se pregunta si "el reconocimiento de la legitimidad del instinto, de la pasión, de lo irracional, ¿no podrían ser la base y la meta de las tareas de nuestros días?" ${ }^{66}$.

El utopismo se comprende también desde la acepción del tiempo. Si en el caso de los revolucionarios se da porque hacen del ser humano una entidad supratemporal, que no reconoce el carácter histórico de la persona, entre los conservadores ocurre que igualmente se oponen a reconocer el fluir de la existencia. La suya es otra utopía, aunque proyectada al pretérito, lo que Hobsbawn llamaría la "invención de la tradición" ${ }^{67}$. Hacer de ésta el modelo a seguir porque, según escribiera Ortega en 1914, los tradicionalistas no son capaces de desarrollar ideas con las que dar sentido al futuro. En lugar de partir de su circunstancia y así mantenerla viva, lo que hacen es idealizar lo ya acaecido y pretender volver a él ${ }^{68}$. Zambrano señala en esta línea que la política conservadora tiene como rasgo esencial traicionar la "esencia dinámica" de la política, llegar a una "nirvánica quietud" frente a la que ella propone incluir el "factor tiempo" en la política ${ }^{69}$. Además como su maestro, buscaba las fuentes psicológicas del conservadurismo. En 1930 Ortega se preocupaba especialmente del hombre-masa revolucionario y fascista, y acudía a la explicación del "señorito satisfecho", pero anteriormente centró su atención en el conservadurismo clásico y escribió en 1908 que su nota esencial es el egoísmo ${ }^{70}$. Esta concepción es la que resucita su discípula, que atribuye a la pereza y al egoísmo las fuentes de la actitud conservadora, dos cuestiones que sin embargo no son tan lejanas de la psicología del hombre masa, puesto que este egoísmo, el creerse autosuficiente, es característica del señorito satisfecho.

${ }^{64}$ En el artículo sobre "Ideas y creencias" (1940) que luego formará parte del libro póstumo El hombre y la gente (1957).

${ }^{65}$ Ortega y Gasset, J., "Fraseología y sinceridad", Obras completas Tomo II..., op. cit., pp. 595-596.

${ }^{66}$ Zambrano, M., "Horizonte del liberalismo", op. cit., pp.85, 87 y 88.

${ }^{67}$ Hobsbawm, E., y Terence, R., La invención de la tradición, Barcelona, Crítica, 2005.

${ }^{68}$ Ortega y Gasset, J., Meditaciones del Quijote. Edición de José Luís Villacañas, Madrid, Biblioteca Nueva, 2004, p. 183 .

69 Zambrano, M., "Horizonte del liberalismo", op. cit., pp. 64-65.

${ }^{70}$ Ortega y Gasset, J., "La solidaridad alemana", Obras completas. Tomo I..., op. cit., pp.136-139, p.137 
Horizonte del liberalismo está publicado en 1930, y en el mismo año aparece $L a$ rebelión de las masas, libro que terminó de editarse por artículos en El Sol en 1928, año en el que nació la Liga de Educación Social. Algo significativo, porque los dos autores meditan sobre la esencia del liberalismo en un contexto antiliberal, el de la Dictadura de Primo de Rivera. Éste intentó la actividad pública desde la Unión Patriótica, sentando las bases de un Estado autoritario contra el que Ortega se puso en guardia, aunque tardíamente. En 1926 escribe que existe una diferencia clave entre el liberalismo y la democracia, y es que si el segundo se refiere a los orígenes del poder, el primero hace lo propio con sus límites ${ }^{71}$. El Estado liberal es el que desarrolla un contrapeso de poderes frente al Estado, evitando una "hiperdemocracia" que rompa el equilibrio entre los dos. A pesar de que defendía la intervención del Estado en materia social, Ortega apostará cada vez con más fuerza por una política que reduzca su tamaño. En el libro de 1930 incluye el capítulo "El mayor peligro, el Estado", porque considera que éste sustituye a la sociedad una vez que las masas lo identifican con su voluntad, excluyendo a las minorías ${ }^{72}$. Significativamente, señala que dos son los movimientos políticos que más claramente muestran esta tendencia: el fascismo, $-y$ cita abiertamente a Mussolini en un momento en el que Primo de Rivera parece querer transformar su dictadura a imagen de la italiana-y lo que llama el "sindicalismo", concepto éste que en 1919 opone al "socialismo", relativo al movimiento obrero que aceptaba el principio liberal ${ }^{73}$.

María Zambrano también se opone a la acción directa, pero su libro muestra dos diferencias. Primero, no critica el papel del Estado en los términos que hace Ortega. Fiel al legado socialista de su padre, se asemeja más al planteamiento liberal-socialista que tenía el propio filósofo años antes. Concibe también la existencia de una dicotomía entre liberalismo y democracia, pero si se ha de sacrificar una, es la segunda. No es la hiperdemocracia lo que más teme, sino un hiperliberalismo, que no nombra así pero expone separando los postulados económicos del liberalismo de los de carácter espiritual. Se ha de elegir entre uno u otro, y plantea superarlo no desde una limitación de la democracia, sino su desarrollo en sentido social. Habla de una "democracia económica", porque "para salvar al primero (al hombre) hay que renunciar a la economía liberal. Para salvar al segundo (los valores) es precisa la libertad". Alude también a una "aristocracia espiritual", la única que puede emanar del liberalismo ético. Pero aunque este concepto tiene orígenes orteguianos, existe una diferencia notable porque es una libertad "fundada, más que en la razón, en la

71 Ortega y Gasset, J., "Notas del vago estío”, Obras completas. Tomo II..., op. cit., pp.531-548, p. 541.

72 Ortega y Gasset, J., La rebelión de las masas, op. cit., pp. 71 y 150.

73 Ortega y Gasset, J., "Ante el movimiento social”, Obras completas. Tomo III (1917-1925), Madrid, Taurus: Fundación José Ortega y Gasset, 2008, pp. 264-280, pp. 264-280. 
fe, en el amor"74. Ortega apeló a una "cultura del amor"75, pero entendida como una integración -el amor es pleonexia- de los españoles bajo la dirección de las élites. Para María Zambrano sin embargo, el amor implica no únicamente los valores "suprahumanos" sino también los "infrahumanos", lo irracional y pasional que se ha de salvar para, al modo de Nietzsche, obrar un milagro que "vuelva a crear el mundo". Con esto a lo que se refiere es a la necesidad de integrar en la política a todos los hombres, y no únicamente a las clases ${ }^{76}$.

No obstante, el liberalismo zambraniano emana directamente del orteguiano. Mucho después, en 1971, escribirá que "su idea de la radical soledad de donde el filosofar emana y de la radicalidad de que el pensar sea dado en la convivencia nos parece ser la idea propia del liberalismo, el fundamento último de toda postura y de toda conducta liberal" ${ }^{77}$. Si Ortega critica al hombre masa, es entre otras cosas porque carece de interioridad, vive alterado, pendiente de estímulos externos y es incapaz de ensimismarse. Frente a ello propone la filosofía como función vital, pero en todo caso, reduciendo la capacidad de su desarrollo a una minoría.

\section{Conclusión}

Según hemos visto, el proyecto liberal de María Zambrano, manifestado históricamente durante la dictadura de Primo de Rivera a través de la Liga de Educación Social, recoge una doble herencia. Por un lado, la de la pedagogía popular y socialista que desarrolló su padre Blas Zambrano. Por otro, la de la pedagogía social elitista de su maestro Ortega y Gasset. La Liga de Educación Social es síntesis de ambos, y con ello también es la proyección de su pensamiento propio que más adelante configurará la Razón poética. Así, hay tres diferencias básicas con respecto a su maestro: una valoración integral de las generaciones mayores -consecuencia de su visión del tiempo-, una apuesta por el protagonismo del pueblo -derivado de su visión de la moral y de la persona-, y una concepción más democrática del liberalismo -consecuencia de los dos vectores anteriores. Finalmente, se ha de indicar que queda por hacer una comparación con la Agrupación al Servicio de la República, cuestión que no hemos tratado por no ser el objetivo de este trabajo, pero que también arrojaría datos sobre las similitudes y diferencias entre los dos filósofos y su compromiso público.

74 Zambrano, M., "Horizonte del liberalismo", op. cit., p.104.

75 Ortega y Gasset, J., "Para la cultura del amor", Obras completas. Tomo II..., op. cit., pp.276-280.

76 Zambrano, M., "Horizonte del liberalismo", op. cit., pp. 87 y 104.

77 Zambrano, M., "Ortega y Gasset y la razón vital”, Escritos sobre Ortega..., op. cit., pp.179-202, p. 200. 


\section{ReferenCias Bibliográficas}

Abellán, J.L., María Zambrano: una pensadora de nuestro tiempo, Rubí, Barcelona, Anthropos, 2006.

Bagur Taltavull, J., La idea de nación en la nueva política orteguiana. Desarrollo y crisis del patriotismo fenomenológico (1909-1916), Madrid, Ápeiron Ediciones, 2016.

Bagur Taltavull, J., "José Ortega y Gasset en el movimiento reformista: la Liga de Educación Política Española como proyección del "patriotismo fenomenológico"”, Ab Initio, no 10 (2014), pp.153-188.

Carey, J., Los intelectuales y las masas: orgullo y prejuicio de la intelectualidad literaria, 1880-1930, Madrid, Siglo XXI, 2007.

Cruz, R., "Pueblo, Parapueblo y Contrapueblo en 1931", Moreno Luzón, J., y Del Rey, F. (eds.), Pueblo y nación. Homenaje a José Álvarez Junco, Madrid, Taurus, 2013, pp.109-125.

Botti, A., Cielo y dinero: el nacionalcatolicismo en España, 1881-1875, Madrid, Alianza Editorial, 2008..

Calvo González, J., "Sobre horizonte del liberalismo (1930), o María Zambrano en claroscuro", Revista telemática de filosofía del derecho (RTFD), no8 (20042005), pp. 99-124.

Cerezo Galán, P., "Ortega y la regeneración del liberalismo: tres navegaciones y un naufragio", en Llano Alonso, F., y Castro Sáenz, A. (eds.), Meditaciones sobre Ortega y Gasset, Madrid, Tebar, 2005, pp. 625-646.

Fondo José Ortega y Gasset, Archivo de la Fundación Ortega-Marañón.

Fox, E. I., "Sobre el liberalismo socialista: cartas inéditas de Maeztu a Ortega, 1908-1915”, Kossof, D. A., y Amor y Vázquez, J. (coords.), Homenaje a Juan López Morillas: de Cadalso a Aleixandre, Madrid, Castalia, 1982, pp. 220-236.

González Cuevas, P.C., "Maeztu y Ortega: dos intelectuales ante la crisis de la Restauración”, Gómez-Ferrer Morant, G., y Sánchez, R. (coords.): Modernizar Espańa: proyectos de reforma y apertura internacional (1898-1914), Madrid, Biblioteca Nueva, 2007, pp.231-252.

Hobsbawm, E., y Terence, R., La invención de la tradición, Barcelona, Crítica, 2005.

López Rey, J., Los estudiantes frente a la dictadura. Madrid, Javier Morata, 1930. Maeztu, R., Defensa de la Hispanidad, Madrid, Homo Legens, 2005. 
Marichal, J., El secreto de España: Ensayos de historia intelectual y política, Madrid, Taurus, 1996.

Marset, J. C., María Zambrano. I, los años de formación, Sevilla, Fundación José Manuel Lara, 2004.

Nietzsche, F., Más allá del bien y del mal, Madrid, Alianza Editorial, 2003.

Ortega y Gasset, J., La rebelión de las masas. Introducción de Julián Marías, Madrid, Espasa-Calpe, 2005.

Ortega y Gasset, J., Meditaciones del Quijote. Edición de José Luís Villacañas, Madrid, Biblioteca Nueva, 2004.

Ortega y Gasset, J., Obras completas. Tomo I (1902-1915), Madrid, Taurus: Fundación José Ortega y Gasset, 2005.

Ortega y Gasset, J., Obras completas. Tomo II (1916), Madrid, Taurus: Fundación José Ortega y Gasset, 2010.

Ortega y Gasset, J., "Ante el movimiento social”, Obras completas. Tomo III (1917-1925), Madrid, Taurus: Fundación José Ortega y Gasset, 2008.

Ortega y Gasset, J., Obras completas. Tomo IV (1926-1931), Madrid, Taurus: Fundación José Ortega y Gasset, 2004.

Redondo, G., Las empresas políticas de José Ortega y Gasset: "El Sol”, "Crisol”, "Luz" (1917-1934), Madrid, Rialp, 1970.

Schorske, C. E., La Viena de fin de siglo: política y cultura, Buenos Aires, Siglo XXI, 2011.

Suárez Cortina, M., El reformismo en España: republicanos y reformistas bajo la monarquía de Alfonso XIII, Madrid, Siglo XXI de España, 1986.

Zambrano, B. J., Artículos, Relatos y Otros Escritos, Diputación Provincial de Badajoz, Badajoz, 1998.

Zambrano, M., Escritos sobre Ortega. Edición, introducción y notas de Ricardo Tejada, Madrid, Trotta, 2011.

Zambrano, M., Obras completas. I, Libros (1930-1939), Barcelona, Galaxia Gutenberg: Círculo de Lectores, 2015.

Zambrano, M., Obras completas. VI, Parte II. Delirio y Destino (1952), Barcelona, Galaxia Gutenberg: Círculo de Lectores, 2014.

DOI: http://doi.org/10.15366/bp2019.22.025

Bajo Palabra. II Época. No 22. Pgs: 459-476 
